\title{
High expression of Mucin13 associates with grimmer postoperative prognosis of patients with non-metastatic clear-cell renal cell carcinoma
}

\author{
Zhiying $X \mathbf{u}^{1, *}$, Yidong Liu ${ }^{1, *}$, Yuanfeng Yang ${ }^{2, *}$, Jieti Wang ${ }^{1}$, Guodong Zhang ${ }^{1}$, Zheng \\ Liu ${ }^{1}$, Hangcheng Fu' ${ }^{1}$, Zewei Wang ${ }^{1}$, Haiou Liu ${ }^{3}$, Jiejie $X u^{1}$ \\ ${ }^{1}$ Department of Biochemistry and Molecular Biology, School of Basic Medical Sciences, Fudan University, Shanghai 200032, \\ China \\ ${ }^{2}$ Department of Urology, Zhongshan Hospital, Fudan University, Shanghai 200032, China \\ ${ }^{3}$ Shanghai Key Laboratory of Female Reproductive Endocrine Related Diseases, Hospital of Obstetrics and Gynecology, Fudan \\ University, Shanghai 200011, China \\ *These authors contributed equally to this work
}

Correspondence to: Haiou Liu, email: liuhaiou@fudan.edu.cn Jiejie Xu, email: jjxufdu@fudan.edu.cn

Keywords: clear-cell renal cell carcinoma, MUC13, overall survival, recurrence-free survival, prognostic biomarker Received: July 06, $2016 \quad$ Accepted: November 22, 2016

Published: November 29, 2016

\section{ABSTRACT}

Background: Mucin13 (MUC13) is a transmembrane glycoprotein that is aberrantly expressed in ovarian and gastro-intestinal tumors, but its role in renal cell carcinoma remains elusive. The purpose of this study is to evaluate the prognostic value of MUC13 expression in patients with non-metastatic clear cell renal cell carcinoma (CCRCC) after surgical resection.

Results: MUC13 high expression was associated with high Fuhrman grade $(p<0.001)$, high SSIGN score $(p=0.011)$, early recurrence $(p<0.001)$ and poor survival $(p<0.001)$. Multivariate Cox regression analysis identified MUC13 expression as an independent prognostic factor for RFS and OS of cCRCC patients. A nomogram integrating MUC13 expression and other independent prognosticators was established to predict RFS and OS of cCRCC patients. Optimal agreement was shown between the predictions and observations in calibration curves.

Matrials and methods: This study enrolled 410 postoperative non-metastatic ccRCC patients at a single institution. Clinicopathologic variables, recurrence-free survival (RFS), and overall survival (OS) were recorded. MUC13 expression was detected by immunohistochemical staining in tumor specimens. Association of MUC13 expression with clinicopathological factors was explored. Kaplan-Meier analysis was performed to compare survival curves. Univariate and multivariate Cox regression models were used to analyze the impact of prognostic factors on RFS and OS. A prognostic nomogram was constructed based on the independent prognostic factors identified by multivariate analysis.

Conclusions: MUC13 high expression is a novel independent adverse prognostic factor of clinical outcome in non-metastatic cCRCC patients after surgery.

\section{INTRODUCTION}

In 2013, renal cell carcinoma became the seventh most common tumor, which was diagnosed in more than 350,000 people worldwide and is associated with more than 140000 deaths per year [1]. The predominant histologic subtype of RCC is clear cell renal cell carcinoma (ccRCC), which represents $75-80 \%$ of all primary kidney malignancies [2]. More than 209,000 new cases and 102,000 deaths are caused by ccRCC per year all over the world and more than one tenth patients diagnosed as ccRCC would occur fatal recurrence within 
5 years after nephrectomy [3, 4]. Currently, several outcome prediction models in RCC have been proposed to evaluate the risk of disease progression of patients after nephrectomy. One widely used model based on features predictive of death from renal cell carcinoma is SSIGN (stage, size, grade, and necrosis) score, which incorporates 1997 TNM stage, tumor size, nuclear grade and histological tumor necrosis [5]. However, ccRCC patients with the similar clinical and pathological features could show a wide variation in clinical outcomes. Even though pathologic factors have been collected, their influence on the prognosis of ccRCC patients remain inconclusive [4]. These facts accentuate the urgent need for the improved predictors of RFS and OS of ccRCC patients.

Mucins are large glycoproteins providing protection and lubrication to epithelial surface of mucosal surfaces (gastrointestinal tract, respiratory tract and reproductive tract). A physical barrier created by mucins can protect epithelial cells from noxious and toxic substances. Human mucin gene family includes 19 members, which can be classified into secreted types and membrane-bound types, whereas the latter ones also participate in cell signaling [6-8]. Alterations in the expression and/or glycosylation of mucins are associated with cellular growth, differentiation, transformation, adhesion, invasion and immune surveillance. The aberrant expression of mucins may have correlation with cancer biology $[6,9,10]$.

Mucin13 (MUC13) is a transmembrane mucin exhibiting abundant $\mathrm{O}-$ and N-glycosylation. Previous study has detected MUC13 mRNA and/or protein in normal tissues like large intestine, trachea, kidney, small intestine, gastric epithelium and esophagus. MUC13 is presented at the apical surface of cells in these tissues [11]. MUC13 consists of a signal peptide, a tandem repeat domain, three epidermal growth factor (EGF)-like domains, a SEA domain and a cytoplasmic tail domain. Tandem repeat (TR) domain, located at the $\mathrm{N}$-terminus of matured MUC13, is composed of 10 TRs rich in serine and threonine residues which can be glycosylated [9]. Highly homologous with the ligand of EGFR, EGF-like domain of MUC13 is rich in cysteine residues [11]. Binding with EGFR and HER2, EGF may activate some signaling pathways resulting in alterations of cell proliferation, cell adhesion, and migration. The cytoplasmic domain of MUC13 includes several potential phosphorylation sites and a protein kinase $\mathrm{C}$ phosphorylation motif [11]. This indicates MUC13 may play an important role in oncogenic cellular signaling pathways. Recently, a number of studies found that MUC13 was overexpressed in many malignancies including colon cancer [12], gastric cancer [13], ovarian cancer [14], esophageal squamous cell carcinoma [15], and pancreatic cancer [16]. High expression of MUC13 also predicts an inferior outcome of patients with colorectal cancer, esophageal squamous cell carcinoma and pancreatic cancer $[12,15,16]$. Currently, the protein level and clinical significance of MUC13 expression in ccRCC remains unknown. Few studies have investigated the correlation between MUC13 expression and clinicopathologic features and outcomes of ccRCC patients.

In this study, we aimed to investigate the clinical significance of MUC13 and the association of MUC13 expression with the clinicopathological features in patients with non-metastatic ccRCC. Additionally, we integrated MUC13 expression and other prognostic variables to predict 3- and 5-year recurrence-free survival and overall survival in non-metastatic ccRCC patients.

\section{RESULTS}

\section{Immunohistochemical findings and association of MUC13 expression with the clinicopathological features}

MUC13 expression levels was identified by immunohistochemical staining in 410 non-metastatic ccRCC specimens. We observed that MUC13 was not only expressed on the apical surface but also located in the cytoplasm and in the nucleus of tumor cells (Figure 1A). The immunohistochemical score (H-score) of immunostaining of tumor tissues differed among each specimen. The average measured $\mathrm{H}$-score of the staining in neoplasm was 95.5 (range 0.6-280.6). The cut-off point for the classification of high/low expression subgroups was 92.0. $198(48.3 \%)$ patients were classified into MUC13 high expression subgroup while the MUC13 low expression subgroup had 212 (51.7\%) patients.

As summarized in Table 1, the mean age in the entire group was $55.21 \pm 12.24$ years old (range 21-86) and the average tumor size was $4.14 \pm 2.26 \mathrm{~cm}$ (range $0.2-15$ ). $70.5 \%$ of patients were male. Table 1 also presents the correlation between MUC13 expression and clinical pathological characteristics. Higher MUC13 expression showed positive association with elevated Fuhrman grade $(p<0.001)$ and higher SSIGN score $(p=0.011)$. We failed to observe the association between other clinical pathological characteristics and MUC13 expression.

\section{Correlations between MUC13 expression and prognosis of ccRCC patients}

At last follow up, median follow-up for patients was 70 months (range 42-74). A mean duration of recurrence-free survival (RFS) was 62 months (range 5-74) and overall survival (OS) was 62 months (range 5-74). Kaplan-Meier analyses log-rank test illustrated that high MUC13 expression could predict earlier recurrence and worse overall survival $(p<0.001, p<0.001$, respectively) (Figure 2A, 2B). 
Furthermore, in order to estimate whether patients can be stratified by MUC13 expression with SSIGN score stratum. Patients were stratified into three risk subgroups: low risk (SSIGN score: $1-2 ; n=305,74.4 \%$ ), intermediate risk (SSIGN score: $3-4 ; n=97,23.7 \%$ ) and high risk (SSIGN score: $5-6 ; n=8,2.0 \%$ ). When the analysis was restricted to low risk group, patients could be significantly stratified with MUC13 expression. High MUC13 expression correlated with decreased recurrencefree survival and reduced overall survival $(p=0.024$, $p=0.019$, respectively) (Figure 3A, 3D). However, in intermediate risk group and high risk group, the difference didn't remain significant in recurrence-free survival or overall survival $(p=0.068, p=0.435, p=0.131$, $p=0.435$, respectively) (Figure 3B, 3C, 3E, 3F).

\section{High MUC13 expression is an independent predictor of poor prognosis in patients with ceRCC}

Univariate analyses were performed for RFS and OS to estimate the clinical significance of MUC13 expression on postoperative survival in the study group. According to the Supplementary Table S1, we observed that high MUC13 expression significantly correlated with reduced RFS and worse OS (HR, 2.952; 95\% CI, 1.588 to 5.488 , $p<0.001$ and HR, 2.890; 95\% CI, 1.614 to 5.172, $p<0.001$, respectively). Additionally, tumor size, $\mathrm{pT}$ stage, Fuhrman grade, LVI, necrosis, sarcomatoid, rahbdoid and ECOG-PS also significantly influenced RFS and OS of patients with ccRCC.

In addition, to obtain the robustness value of MUC13 expression, multivariate Cox regression analyses were performed to derive risk evaluation related to OS and RFS with cilnicopathologic parameters derived from univariate analyses Table 2. PT stage, Fuhrman grade, LVI and necrosis, high MUC13 expression (HR, 2.082; 95\% CI, 1.115 to $3.889, p=0.021$ ) were independent predictors of RFS. Together with pT stage, Fuhrman grade, LVI, necrosis and rahbdoid, high MUC13 expression (HR, 2.287; $95 \% \mathrm{CI}, 1.169$ to $4.477, p=0.016$ ) also remained an independent prognostic factor for OS. In total, our study illustrated that MUC13 expression might be an independent indicator to predict recurrence-free survival and overall survival of non-metastatic ccRCC patients. The C-index of the SSIGN was 0.7440 for OS and 0.7336 for RFS, and improved to 0.7933 for OS $(p=0.009)$ and 0.7836 for RFS $(p=0.006)$ when MUC13 expression was added.

\section{Construction and validation of prognostic nomogram for RFS and OS}

Significant prognostic factors were concluded from multivariate Cox regression analyses of OS and RFS to establish nomogram (Figures 4A, 5A). The calibration plot for the nomogram presented an optimal agreement between the predicted and actual observation for the RFS and $\mathrm{OS}$ at 3-yr and 5-yr (Figures 4B, 4C, 5B, 5C). We also preformed Harrell's c-index to evaluate the prognostic accuracy for the nomogram. The Harrell's c-index for the nomogram model to predict 3-year and 5-year overall survival were 0.9668 and 0.8697 , respectively. And the Harrell's c-index for the nomogram model to predict 3 -year and 5-year recurrence-free survival were 0.9743 and 0.8701 , respectively.

\section{DISCUSSION}

As far as we know, this study was the first investigation illustrating the correlation between high MUC13 expression and unfavorable prognosis of postoperative non-metastatic ccRCC patients. We found
A MUC13 high expression

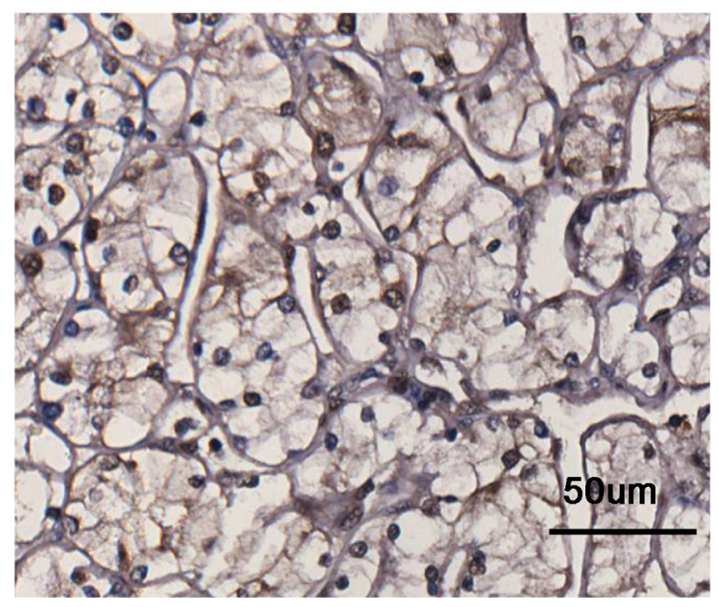

MUC13 low expression

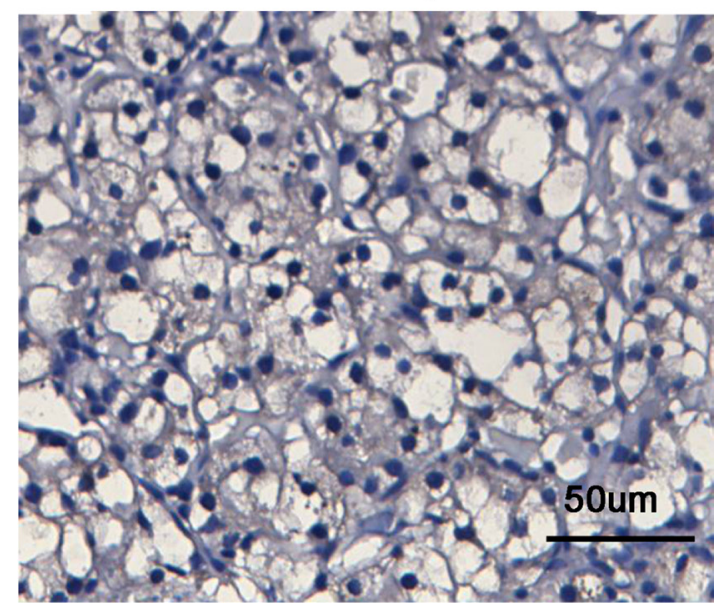

Figure 1: MUC13 expression in non-metastatic clear-cell renal cell carcinoma (ccRCC) tissues. (A) Representative photographs of immunohistochemical (IHC) staining in ccRCC tissues with differential expression level of MUC13. Scale bar $=50 \mu \mathrm{m}$. 
Table 1: Correlation between MUC13 expression and patient characteristics

\begin{tabular}{|c|c|c|c|c|c|}
\hline \multirow{2}{*}{ Characteristic } & \multicolumn{2}{|c|}{ Patients $(n=410)$} & \multicolumn{2}{|c|}{ MUC13 expression } & \multirow{2}{*}{$P^{a}$} \\
\hline & Number & $\%$ & Low $(n=212)$ & $\operatorname{High}(n=198)$ & \\
\hline $\begin{array}{l}\text { Age at surgery, years } \\
\text { Mean } \pm \text { SD }\end{array}$ & \multicolumn{2}{|c|}{$55.21 \pm 12.24$} & $53.16 \pm 12.64$ & $57.40 \pm 11.43$ & 0.152 \\
\hline $\begin{array}{l}\text { Gender } \\
\text { Female } \\
\text { Male }\end{array}$ & $\begin{array}{l}121 \\
289\end{array}$ & $\begin{array}{l}29.5 \\
70.5\end{array}$ & $\begin{array}{c}65 \\
147\end{array}$ & $\begin{array}{c}56 \\
142\end{array}$ & 0.675 \\
\hline $\begin{array}{l}\text { Tumor size, } \mathrm{cm}^{\mathrm{b}} \\
\text { Mean } \pm \mathrm{SD}\end{array}$ & \multicolumn{2}{|c|}{$4.14 \pm 2.26$} & $3.02 \pm 2.13$ & $4.39 \pm 2.38$ & 0.109 \\
\hline $\begin{array}{l}\text { pT-stage } \\
1 \\
2 \\
3\end{array}$ & $\begin{array}{c}290 \\
24 \\
96\end{array}$ & $\begin{array}{c}70.7 \\
5.9 \\
23.4\end{array}$ & $\begin{array}{l}156 \\
15 \\
41\end{array}$ & $\begin{array}{c}134 \\
9 \\
55\end{array}$ & 0.094 \\
\hline $\begin{array}{l}\text { Fuhrman grade } \\
\qquad \begin{array}{l}1 \\
2 \\
3 \\
4\end{array}\end{array}$ & $\begin{array}{c}74 \\
197 \\
93 \\
46\end{array}$ & $\begin{array}{l}18.0 \\
48.1 \\
22.7 \\
11.2\end{array}$ & $\begin{array}{c}57 \\
101 \\
43 \\
11\end{array}$ & $\begin{array}{l}17 \\
96 \\
50 \\
35\end{array}$ & $<0.001$ \\
\hline $\begin{array}{l}\text { LVI } \\
\text { Absent } \\
\text { Present }\end{array}$ & $\begin{array}{l}306 \\
104\end{array}$ & $\begin{array}{l}74.6 \\
25.4\end{array}$ & $\begin{array}{c}160 \\
52\end{array}$ & $\begin{array}{l}146 \\
52\end{array}$ & 0.772 \\
\hline $\begin{array}{l}\text { Necrosis } \\
\text { Absent } \\
\text { Present }\end{array}$ & $\begin{array}{c}331 \\
79\end{array}$ & $\begin{array}{l}80.7 \\
19.3\end{array}$ & $\begin{array}{c}172 \\
40\end{array}$ & $\begin{array}{c}159 \\
39\end{array}$ & 0.930 \\
\hline $\begin{array}{l}\text { Sarcomatoid } \\
\text { Absent } \\
\text { Present }\end{array}$ & $\begin{array}{c}402 \\
8\end{array}$ & $\begin{array}{c}98.0 \\
2.0\end{array}$ & $\begin{array}{c}209 \\
3\end{array}$ & $\begin{array}{c}193 \\
5\end{array}$ & 0.649 \\
\hline $\begin{array}{c}\text { Rahbdoid } \\
\text { Absent } \\
\text { Present }\end{array}$ & $\begin{array}{c}394 \\
16\end{array}$ & $\begin{array}{c}96.1 \\
3.9\end{array}$ & $\begin{array}{c}207 \\
5\end{array}$ & $\begin{array}{c}187 \\
11\end{array}$ & 0.157 \\
\hline $\begin{array}{c}\text { ECOG-PS } \\
\quad 0 \\
\geq 1\end{array}$ & $\begin{array}{c}343 \\
67\end{array}$ & $\begin{array}{l}83.7 \\
16.3\end{array}$ & $\begin{array}{c}183 \\
29\end{array}$ & $\begin{array}{c}160 \\
38\end{array}$ & 0.169 \\
\hline $\begin{array}{l}\text { SSIGN } \\
1 \\
2 \\
3\end{array}$ & $\begin{array}{c}305 \\
97 \\
8\end{array}$ & $\begin{array}{c}74.4 \\
23.6 \\
2.0\end{array}$ & $\begin{array}{c}169 \\
39 \\
2\end{array}$ & $\begin{array}{c}136 \\
58 \\
6\end{array}$ & 0.011 \\
\hline
\end{tabular}

Abbreviations: $\mathrm{MUC13}=$ mucin13; $\mathrm{SD}=$ standard deviation;

LVI = Lymphovascular invasion; ECOG-PS = Eastern Cooperative Oncology Group performance status;

SSIGN $=$ stage, size, grade and necrosis.

${ }^{\mathrm{a}} P<0.05$ is considered statistically significant.

${ }^{b}$ The results of continuous variables are presented as mean $\pm \mathrm{SD}$ (standard deviation).

that incorporation of MUC13 expression into SSIGN model could improve the stratification of patients and provide more prognostic information. Our study demonstrated that MUC13 expression was positively correlated to Fuhrman grade, which implies that MUC13 might be associated with differentiation of ccRCC. In addition, MUC13 expression was evaluated as an independent prognostic factor and could be incorporated into a nomogram with other established pathologic factors. The study indicated that MUC13 might promote the tumorigenesis and development of ccRCC.

MUC13 is a high-molecular-weight glycoproteins of mucin family. The existence of TR domain-the hallmark feature of this family, indicates that the extracellular part of the protein may be capable of blocking cell-cell adhesion and cell adhesion to the ECR through protruding 
Table 2: Multivariate cox regression analysis of recurrence-free survival and overall survival

\begin{tabular}{|c|c|c|c|c|}
\hline \multirow{2}{*}{ Characteristic } & \multicolumn{2}{|c|}{$\begin{array}{l}\text { Recurrence-free survival } \\
\quad(n=410, \text { event }=55)\end{array}$} & \multicolumn{2}{|c|}{$\begin{array}{c}\text { Overall survival } \\
(n=410, \text { event }=49)\end{array}$} \\
\hline & Hazard Ratio (95\% CI) & $P^{a}$ & Hazard Ratio (95\% CI) & $P^{a}$ \\
\hline Tumor size, cm & $1.368(1.192-1.571)$ & $<\mathbf{0 . 0 0 1}$ & $1.327(1.155-1.525)$ & $<0.001$ \\
\hline $\begin{array}{l}\text { pT-stage } \\
1 \\
2 \\
3\end{array}$ & $\begin{array}{c}\text { Reference } \\
1.528(0.434-5.378) \\
3.177(1.547-6.526)\end{array}$ & $\begin{array}{l}\mathbf{0 . 0 0 6} \\
0.509 \\
\mathbf{0 . 0 0 2}\end{array}$ & $\begin{array}{c}\text { Reference } \\
3.136(0.933-10.542) \\
4.826(2.272-10.251)\end{array}$ & $\begin{array}{r}0.065 \\
<\mathbf{0 . 0 0 1}\end{array}$ \\
\hline $\begin{array}{l}\text { Fuhrman grade } \\
\qquad \begin{array}{l}1 \\
2 \\
3 \\
4\end{array}\end{array}$ & $\begin{array}{c}\text { Reference } \\
1.232(0.351-4.323) \\
2.366(0.649-8.618) \\
4.959(1.350-18.213)\end{array}$ & $\begin{array}{l}\mathbf{0 . 0 0 4} \\
\\
0.745 \\
0.192 \\
\mathbf{0 . 0 1 6}\end{array}$ & $\begin{array}{c}\text { Reference } \\
1.028(0.289-3.657) \\
1.593(0.416-6.098) \\
3.600(0.950-13.642)\end{array}$ & $\begin{array}{l}0.966 \\
0.497 \\
0.060\end{array}$ \\
\hline $\begin{array}{l}\text { LVI } \\
\text { Absent } \\
\text { Present }\end{array}$ & $\begin{array}{c}\text { Reference } \\
2.973(1.591-5.556)\end{array}$ & $<0.001$ & $\begin{array}{c}\text { Reference } \\
3.355(1.712-6.574)\end{array}$ & $<0.001$ \\
\hline $\begin{array}{l}\text { Necrosis } \\
\text { Absent } \\
\text { Present }\end{array}$ & $\begin{array}{c}\text { Reference } \\
2.679(1.422-5.049)\end{array}$ & 0.002 & $\begin{array}{c}\text { Reference } \\
2.515(1.258-5.028)\end{array}$ & 0.009 \\
\hline $\begin{array}{l}\text { Sarcomatoid } \\
\text { Absent } \\
\text { Present }\end{array}$ & $\begin{array}{c}\text { Reference } \\
2.394(0.659-8.692)\end{array}$ & 0.184 & $\begin{array}{c}\text { Reference } \\
2.150(0.576-8.030)\end{array}$ & 0.255 \\
\hline $\begin{array}{r}\text { Rahbdoid } \\
\text { Absent } \\
\text { Present }\end{array}$ & $\begin{array}{c}\text { Reference } \\
1.514(0.602-3.809)\end{array}$ & 0.378 & $\begin{array}{c}\text { Reference } \\
2.990(1.264-7.073)\end{array}$ & 0.013 \\
\hline $\begin{array}{l}\text { ECOG-PS } \\
\quad 0 \\
\quad \geq 1\end{array}$ & $\begin{array}{c}\text { Reference } \\
1.479(0.761-2.875)\end{array}$ & 0.248 & $\begin{array}{c}\text { Reference } \\
1.605(0.784-3.286)\end{array}$ & 0.196 \\
\hline $\begin{array}{l}\text { MUC13 } \\
\text { Low } \\
\text { High }\end{array}$ & $\begin{array}{c}\text { Reference } \\
2.082(1.115-3.889)\end{array}$ & 0.021 & $\begin{array}{c}\text { Reference } \\
2.287(1.169-4.477)\end{array}$ & 0.016 \\
\hline
\end{tabular}

Abbreviations: MUC13 = mucin13; CI = confidence interval;

LVI = Lymphovascular invasion; ECOG-PS = Eastern Cooperative Oncology Group performance status.

${ }^{a} P<0.05$ is considered statistically significant.

more than 200 to $2,000 \mathrm{~nm}$ above the cancer cell surface. Hence, the overexpression of mucins may be involved in the exfoliation, dissemination, and invasion of cancer cells [6]. Consistent with our results, a growing body of literatures found that overexpression and aberrant localization of MUC13 was observed in other cancers [12-16]. One of these studies illustrated that exogenous MUC13 expression correlated with remarkable reduction in cell-cell adhesion and significantly $(p<0.05)$ increases cell motility, proliferation, and tumorigenesis in a xenograft mouse model system with ovarian cancer. And the cellular characteristics were associated with upregulation of HER-2, p21-activated kinase 1, and p38 protein expression [14]. This phenomenon implies that the combination of HER-2 and EDF-like domain may be implicated in the modulations of cellular characteristic and
MUC13 may play a significant role in the development of cancer. But the correlation between MUC13 and ccRCC cellular characteristic still needs more investigation.

Mucins have been demonstrated as potential tumor markers and therapeutic targets [17-19], because of their potential for altered glycosylation patterns and abundant expression in cancer. Our previous studies found that high expression of mucin $3 \mathrm{~A}$ or mucin 7 can predict poor prognosis of ccRCC patients while decreased expression of mucin 4 or mucin 18 is associated with poor outcome of ccRCC patients [20-23]. Increased expression of mucin 1 was observed in ccRCC and may play a role in renal cancer progression [24]. The biological role of mucin1 in renal cancer has been studied for a long time and was found as an actor in epithelial-mesenchymal transition which may enable invasion and initiate metastasis of 
renal carcinoma [25]. Under hypoxia, binding of HIF-1 alpha and mucin 1 promoter leads to overexpression of mucin 1 which can promote the invasive and migration properties of ccRCC [26]. And mucin1-C nuclear location drives invasiveness of renal cancer cell by a sheddase/ gamma secretase dependent mechanism [27]. Previous study demonstrated that blockage of MUC13 decreased sensitivity of esophageal squamous cell carcinoma cell

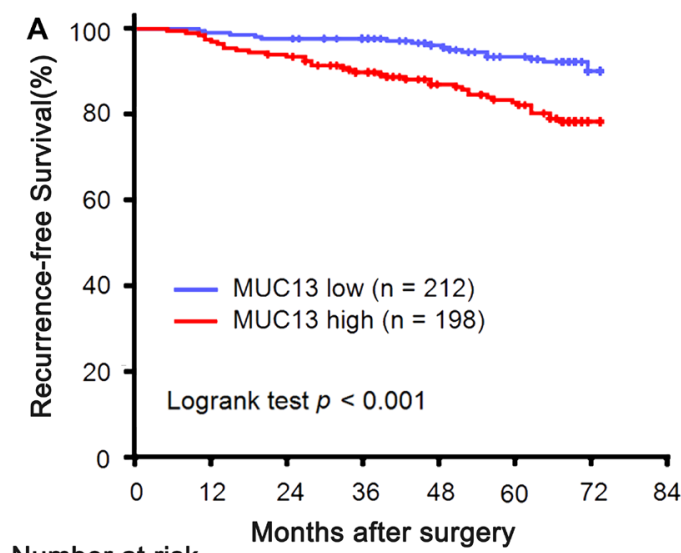

Number at risk

Months after surgery

$\begin{array}{rlllllll}\text { MUC13 low } & & & & & & & \\ 212 & 210 & 207 & 198 & 182 & 167 & 16 & 0 \\ \text { MUC13 high } & & & & & & & \\ 198 & 192 & 184 & 165 & 145 & 134 & 23 & 0\end{array}$

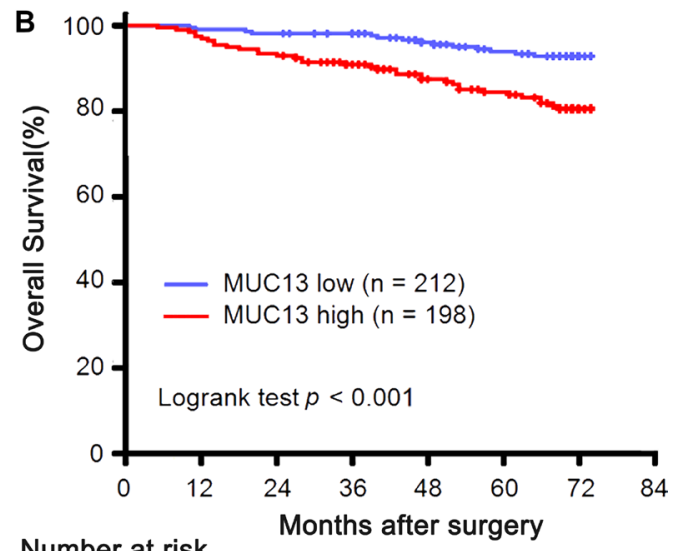

Number at risk

MUC13 low

$\begin{array}{cccccccc}\text { MUC13 high } & & & & & & & \\ 198 & 192 & 184 & 167 & 147 & 135 & 26 & 0\end{array}$

Figure 2: Analysis of RFS and OS of patients with non-metastatic ccRCC according to MUC13 expression in all patients. (A) Kaplan-Meier analysis of RFS $(n=410, p<0.001)$. (B) Kaplan-Meier analysis of OS $(n=410, p<0.001)$. $P$-value was calculated by log-rank test.
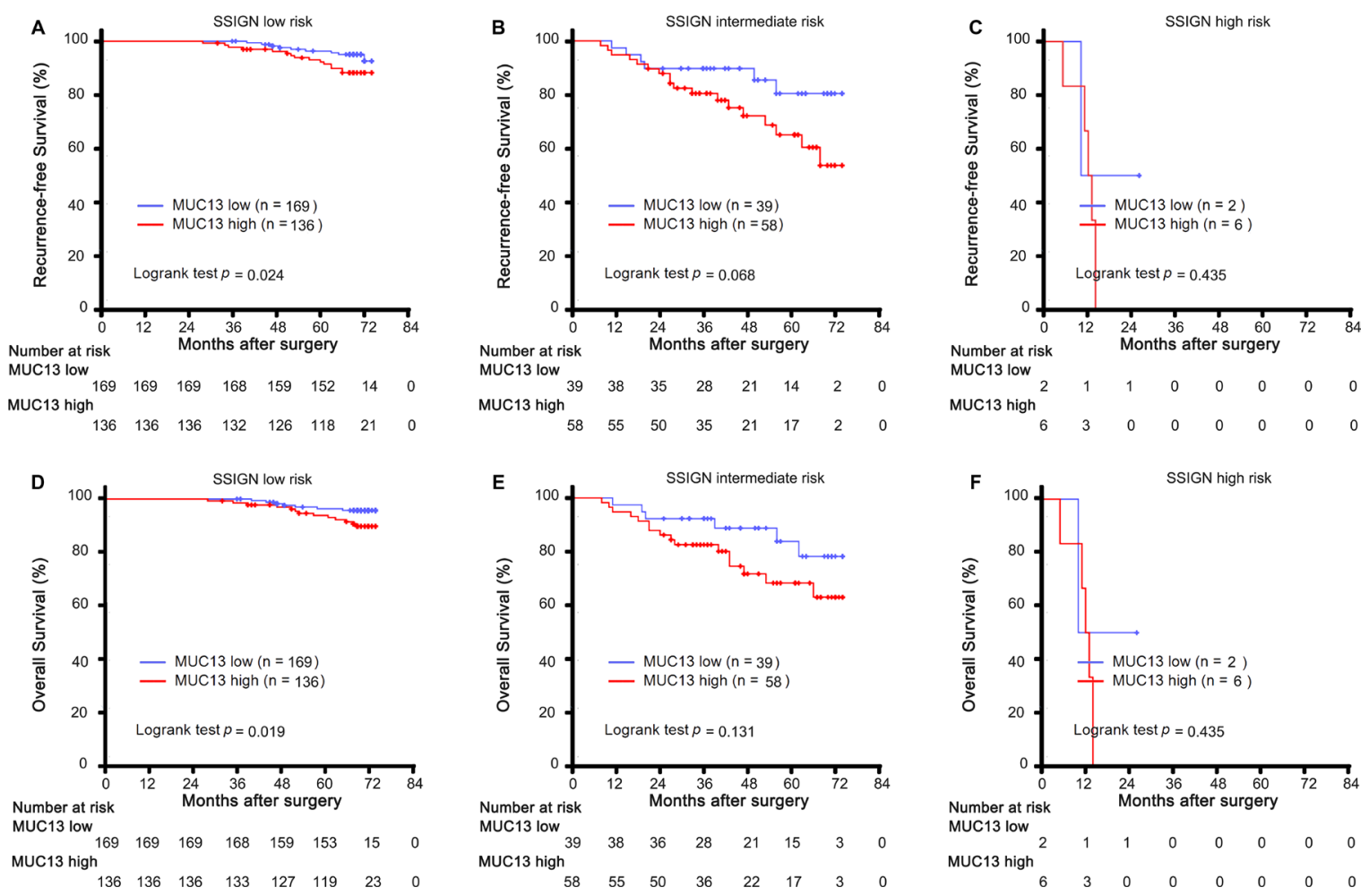

Figure 3: Analysis of RFS and OS according to MUC13 expression in each SSIGN risk group. (A-C) Kaplan-Meier analysis of RFS according to MUC13 expression in (A) SSIGN low risk, (B) SSIGN intermediate risk, (C) SSIGN high risk patients. (D-F) Kaplan-Meier analysis of OS according to MUC13 expression in (D) SSIGN low risk, (E) SSIGN intermediate risk, (F) SSIGN high risk patients. $P$-value was calculated by log-rank test. 
lines to paclitaxel [28]. MUC13 can promote nuclear factor $-\kappa \mathrm{B}(\mathrm{NF}-\kappa \mathrm{B})$ activation to prolong colorectal cancer cell survival. High expression of cytoplasmic MUC13 and $\mathrm{NF}-\kappa \mathrm{B}$ is associated with progression and metastases of colorectal cancer. Silencing MUC13 can improve the sensitivity of colorectal cancer cells to chemotherapy. These indicate that MUC13 may become a novel prognostic biomarker and predict for chemosensitivity of cancer [29]. Extracellular luminal staining data of a previous study implied that it was possible for MUC13 to release into the secretions and/or blood after shedding from the ovarian cancer cells [14]. Therefore, MUC13 serum and urine immunoassay might be developed as a screening method or diagnostic marker for cancer. High expression of MUC13 is regard as an independent prognostic indicator of early-staged gastric cancer [30]. In the current study, our initial work revealed that only the patients in SSIGN low risk subgroups could be significantly stratified by MUC13 expression. Therefore MUC13 may provide more details to clinicians for changing the frequency of follow-up and improving therapeutic approaches for SSIGN low risk subgroups ccRCC patients. Recently, a study found that high expression of MUC13 was associated with deceased expression of tumor suppressor, p53, and also the activation or expression of crucial oncogenes, HER2, PAK1, ERK, Akt, and S100A4 [16].
Another study demonstrated that miR-145 can suppress tumor growth of pancreatic cancer through its inhibitory effects on MUC13 [31]. These implied that MUC13 might become an effective therapeutic target for cancer.

Although we have demonstrated the clinical significance of MUC13 expression in ccRCC, it is undeniable that several limitations in this study warrant further discussion. Firstly, we have to acknowledge the statistical limitations of the study due to small number of patients, especially for whom with advanced disease. Secondly, an independent external cohort is required to confirm our research findings. Finally, further researches are required to confirm the mechanisms of MUC13 in the tumorigenesis of ccRCC and its potential to become a drug target.

In conclusion, our observations revealed that high MUC13 expression can independently predicts unfavorable postoperative RFS and OS for ccRCC patients. A prognostic nomogram integrating MUC13 expression and other pathologic factors was constructed to predict the RFS and OS of ccRCC patients. Furthermore, MUC13 might become an immunotherapeutic target for ccRCC. An intensive focus is required to confirm the biological mechanism of MUC13 involved in ccRCC progression and management, which may reveal promising therapeutic strategies for ccRCC treatment.

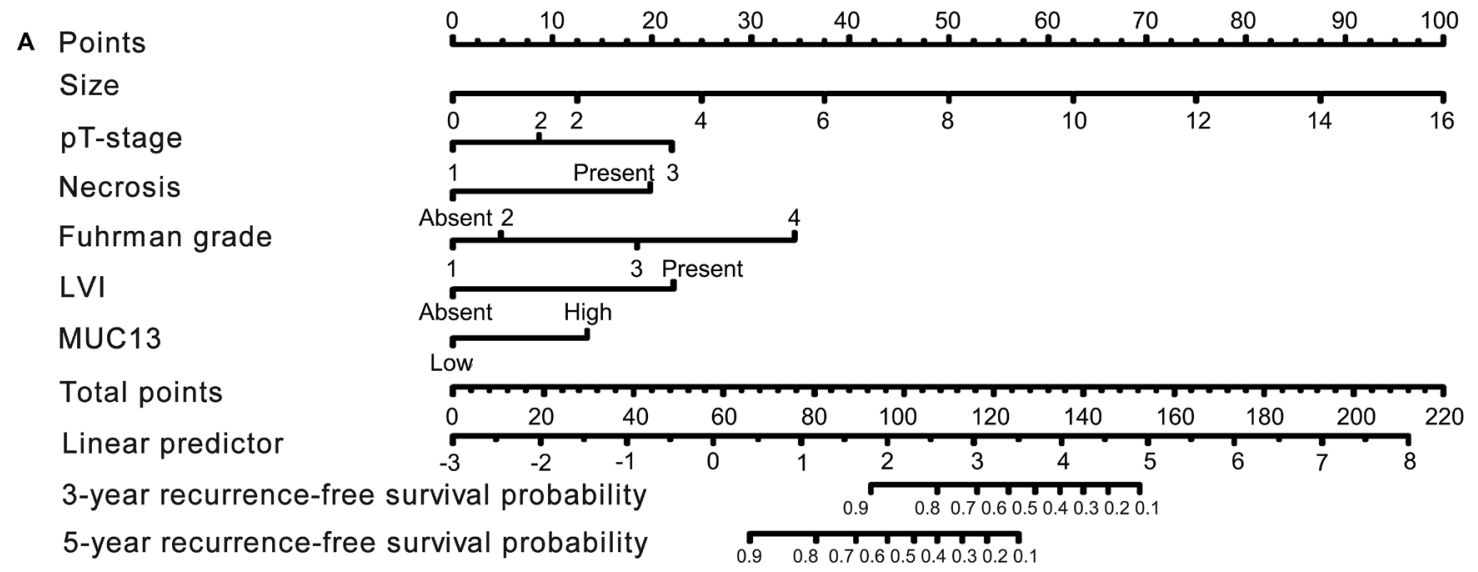

B

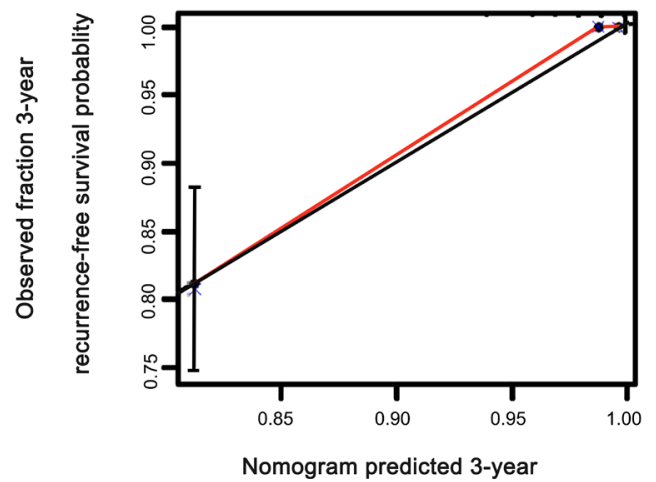

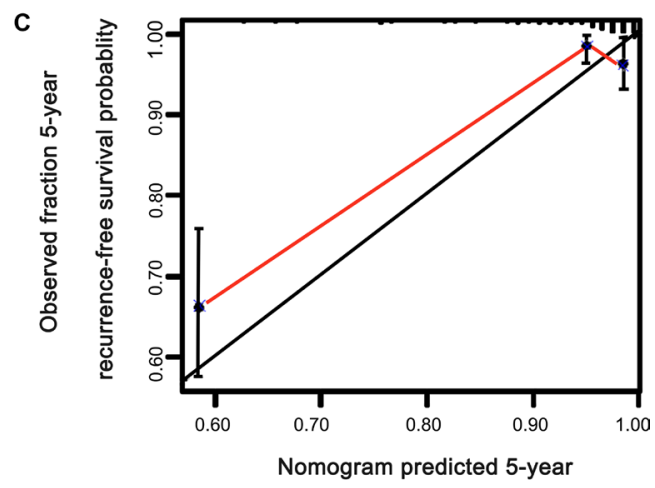

Figure 4: Nomogram and calibration plot for RFS prediction in patients with non-metastatic ccRCC. (A) Five independent prognostic factors were entered into the nomogram to predict 3- and 5-year recurrence-free survival. The calibration plots for predicting RFS at (B) 3 years, (C) 5 years. 


\section{MATERIALS AND METHODS}

\section{Patients}

410 patients diagnosed with non-metastatic clear-cell RCC histopathologically were enrolled in the study. The patients underwent partial or radical nephrectomy between Jan 7, 2008 and Dec 23, 2009 at Zhongshan Hospital, Fudan University, Shanghai, China. Patients who have confirmed histopathology diagnosis after nephrectomy, complete available follow-up data and suffered from no comorbidities, received no adjuvant post-operative anticancer therapy are included in this study. And patients were excluded based on the following criteria: (a) incomplete follow-up data; (b) bilateral disease and familial RCC; (c) preoperative neoadjuvant and/or postoperative adjuvant therapy; (d) death within the first month after operation. Corresponding Formalin Fixed Paraffin Embedded specimen of tumor mass $\left(\geq 1 \mathrm{~cm}^{3}\right)$ were achieved and kept in the archives. The specimen were classified into different histological subtypes according to 2014 EAU guidelines [32]. No positive margins were reported in the pathological reports of patients.

All clinicopathologic and baseline demographic characteristics factors and follow-up outcomes were collected in the database. The pT-stage was carried out based on TNM classification of AJCC (American Joint Committee on Cancer) in 2010 [33]. Fuhrman grade, LVI (lymphovascular invasion), necrosis, sarcomatoid features and rahbdoid features were recorded according the 2012 ISUP (International Society of Urological Pathology) consensus [4]. Eastern ECOG-PS (Eastern Cooperative Oncology Group - performance status) were estimated as previously reported [34]. SSIGN scores were evaluated according to original scoring algorithm [35]. Overall survival (OS) was defined as the time from surgery to the death or the last follow-up. Recurrencefree survival (RFS) was calculated from the date of surgery to the first RCC recurrence. Data were censored if the patients kept alive at the end of the follow-up. The study had achieved the informed consent of all patients and the approval from the institutional ethical review boards of hospital.

\section{Tissue microarray construction and immunohistochemistry}

Tissue microarrays (TMA) were constructed as previously described [20]. Duplicate $1.0-\mathrm{mm}$ tissue cores from two different areas were used to

A Points
Size
PT-stage
Fuhrman grade
Necrosis
Rahbdoid
LVI
MUC13
Total points
Linear predictor
3-year survival probability
5-year survival probability

B

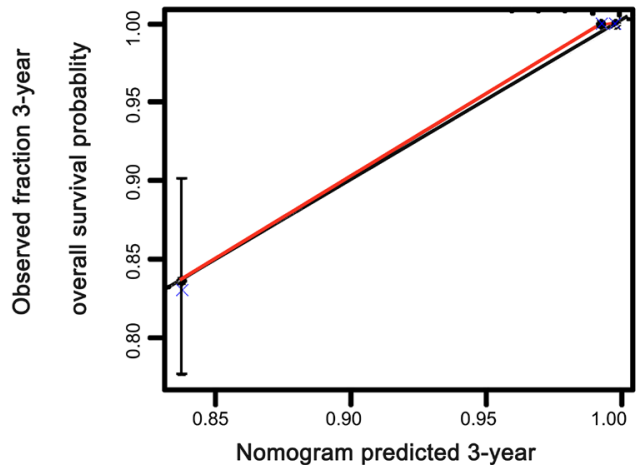

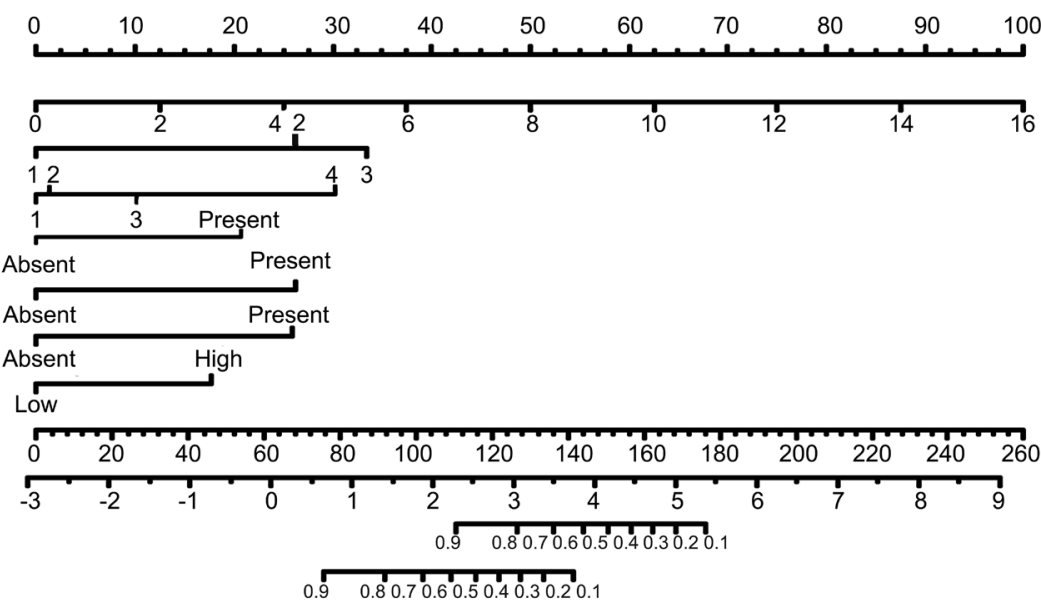

C

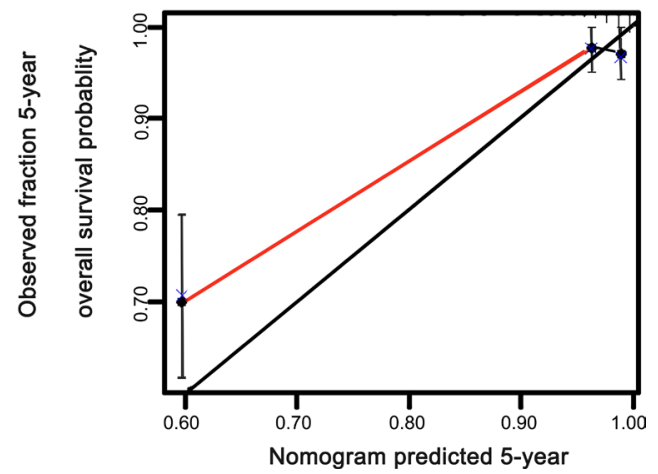

Figure 5: Nomogram and calibration plot for OS prediction in patients with non-metastatic ccRCC. (A) Six independent prognostic factors were entered into the nomogram to predict 3- and 5-year overall survival. The calibration plots for predicting OS at (B) 3 years, (C) 5 years. 
construct the TMA. Primary Anti-MUC13 antibody (1:500; Abam, Cambridge, MA, USA) are applied for the IHC (immunohistochemical) staining. A fully automated microscopy system (Leica DM6000 B, Leica Microsystems GmbH, Mannheim, Germany) was used to scan immunohistochemistry sections. We measured the density of positive staining by Leica Ariol 4.0 software. These mi-quantitative $\mathrm{H}$-score, ranged from 0 to 300, was derived from the multiplication of the staining intensities (0: negative, 1: weak staining, 2: moderate staining, 3: strong staining) and the distributions (0-100\%) For each specimen, the mean score of duplicates was adopted for statistical analyses. The H-score was evaluated by two independent pathologists without the knowledge of clinicopathological information. The agreement between the two twp was excellent, which was evaluated by kappa value $(0.85)$.

\section{Statistical analysis}

Analyses were performed with X-tile software version 3.6.1 (Yale University, New Haven, CT), MedCalc Software version 12.7.0 (MedCalc, Mariakerke, Belgium), SPSS version 21.0 (IBM, Armonk, NY), Stata SE version 14 (Stata, College Station, TX) and R software packages version 3.2.3 (The R Foundation for Statistical Computing, http://www.r-project.org/). A minimum $P$-value approach calculated by X-tile software was applied to determine the cut-off point. Correlations between MUC13 expression and clinicopathologic variables were analyzed by Student's $t$ test, Pearson $\chi 2$ test and Fisher's exact test, as appropriate. Survival curves were determined by Kaplan-Meier analysis and compared by Log-rank test. Univariate and multivariate analyses were performed by the stepwise Cox proportional hazard regression model. Harrell's concordance index (C-index) was used to evaluate the predictive accuracy of parameters and prognostic models. Nomogram was constructed as the prognostic model whose accuracy was evaluated by the Calibration plot. All data tests were twosided and differences were considered significant when $p$ value was under 0.05 .

\section{Abbreviations}

MUC13 = Mucin13, ccRCC $=$ Clear-cell renal carcinoma, RFS = Recurrence-free survival, OS = Overall survival, SSIGN = Mayo clinic stage, size, grade, and necrosis score, $\mathrm{RCC}=$ Renal cell carcinoma, $\mathrm{EGF}=$ Epidermal growth factor, TR domain $=$ Tandem repeat domain, HER2 = Human epidermal growth factor receptor 2, LVI = Lymphovascular invasion, ECOG $\mathrm{PS}=$ Eastern cooperative oncology group performance status, $\mathrm{C}$ index $=$ Harrell's concordance index, H-score $=$ immunohistochemical score, $\mathrm{HR}=$ Hazard ratio.

\section{ACKNOWLEDGMENTS}

This study was funded by grants from National Key Projects for Infectious Diseases of China (2012ZX10002012-007, 2016ZX10002018-008), National Natural Science Foundation of China (31270863, 81471621, 81472227,31570803 and 81671628) and Program for New Century Excellent Talents in University (NCET-13-0146). All these study sponsors have no roles in the study design, in the collection, analysis, and interpretation of data.

\section{CONFLICTS OF INTEREST}

The authors declare no conflicts of interest.

\section{Authors' contributions}

Z. Xu for acquisition of data, analysis and interpretation of data, statistical analysis and drafting of the manuscript; Y. Liu, Y. Yang, J. Wang, G. Zhang, Z. $\mathrm{Liu}, \mathrm{H}$. Fu and $\mathrm{Z}$. Wang for technical and material support; H. Liu and J. Xu for study concept and design, analysis and interpretation of data, drafting of the manuscript, obtained funding and study supervision. All authors read and approved the final manuscript.

\section{REFERENCES}

1. Capitanio U, Montorsi F. Renal cancer. Lancet. 2016; 387:894-906.

2. Cohen HT, McGovern FJ. Renal-cell carcinoma. Nejm. 2005; 353:2477-2490.

3. Gupta K, Miller JD, Li JZ, Russell MW, Charbonneau C. Epidemiologic and socioeconomic burden of metastatic renal cell carcinoma (mRCC): a literature review. Cancer Treat Rev. 2008; 34:193-205.

4. Delahunt B, Cheville JC, Martignoni G, Humphrey PA, Magi-Galluzzi C, McKenney J, Egevad L, Algaba F, Moch H, Grignon DJ, Montironi R, Srigley JR and Members of the IRTP. The International Society of Urological Pathology (ISUP) grading system for renal cell carcinoma and other prognostic parameters. Am J Surg Pathol. 2013; 37:1490-1504.

5. Frank I, Blute ML, Cheville JC, Lohse CM, Weaver AL, Zincke H. An outcome prediction model for patients with clear cell renal cell carcinoma treated with radical nephrectomy based on tumor stage, size, grade and necrosis: the SSIGN score. J Urology. 2002; 168:2395-2400.

6. Hollingsworth MA, Swanson BJ. Mucins in cancer: protection and control of the cell surface. Nat Rev Cancer. 2004; 4:45-60.

7. Gendler SJ, Spicer AP. Epithelial mucin genes. Annu Rev Physiol. 1995; 57:607-634. 
8. Singh PK, Hollingsworth MA. Cell surface-associated mucins in signal transduction. Trends Cell Biol. 2006; $16: 467-476$.

9. Maher DM, Gupta BK, Nagata S, Jaggi M, Chauhan SC. Mucin 13: structure, function, and potential roles in cancer pathogenesis. Mol Cancer Res. 2011; 9:531-537.

10. Chauhan SC, Singh AP, Ruiz F, Johansson SL, Jain M, Smith LM, Moniaux N, Batra SK. Aberrant expression of MUC4 in ovarian carcinoma: diagnostic significance alone and in combination with MUC1 and MUC16 (CA125). Modern Pathol. 2006; 19:1386-1394.

11. Williams SJ, Wreschner DH, Tran M, Eyre HJ, Sutherland GR, McGuckin MA. Muc13, a novel human cell surface mucin expressed by epithelial and hemopoietic cells. J Biol Chem. 2001; 276:18327-18336.

12. Walsh MD, Young JP, Leggett BA, Williams SH, Jass JR, McGuckin MA. The MUC13 cell surface mucin is highly expressed by human colorectal carcinomas. Hum Pathol. 2007; 38:883-892.

13. Shimamura T, Ito H, Shibahara J, Watanabe A, Hippo Y, Taniguchi H, Chen Y, Kashima T, Ohtomo T, Tanioka F, Iwanari H, Kodama T, Kazui T, et al. Overexpression of MUC13 is associated with intestinal-type gastric cancer. Cancer Sci. 2005; 96:265-273.

14. Chauhan SC, Vannatta K, Ebeling MC, Vinayek N, Watanabe A, Pandey KK, Bell MC, Koch MD, Aburatani H, Lio Y, Jaggi M. Expression and functions of transmembrane mucin MUC13 in ovarian cancer. Cancer Res. 2009; 69:765-774.

15. Wang H, Shen L, Lin Y, Shi Q, Yang Y, Chen K. The expression and prognostic significance of Mucin 13 and Mucin 20 in esophageal squamous cell carcinoma. J Cancer Res Ther. 2015; 11:C74-79.

16. Chauhan SC, Ebeling MC, Maher DM, Koch MD, Watanabe A, Aburatani H, Lio Y, Jaggi M. MUC13 mucin augments pancreatic tumorigenesis. Mol Cancer Ther. 2012; 11:24-33.

17. Chauhan SC, Kumar D, Jaggi M. Mucins in ovarian cancer diagnosis and therapy. J Ovarian Res. 2009; 2:21.

18. Kufe DW. Mucins in cancer: function, prognosis and therapy. Nat Rev Cancer. 2009; 9:874-885.

19. Singh R, Bandyopadhyay D. MUC1: a target molecule for cancer therapy. Cancer Biol Ther. 2007; 6:481-486.

20. Bai Q, Liu L, Long QL, Xia Y, Wang JJ, Xu JJ, Guo JM. Decreased expression of mucin 18 is associated with unfavorable postoperative prognosis in patients with clear cell renal cell carcinoma. Int J Clin Exp Patho. 2015; 8:11005-11014.

21. NguyenHoang S, Liu Y, Xu L, Chang Y, Zhou L, Liu Z, Lin Z, Xu J. High mucin-7 expression is an independent predictor of adverse clinical outcomes in patients with clear-cell renal cell carcinoma. Tumour Biol. 2016.

22. Niu T, Liu Y, Zhang Y, Fu Q, Liu Z, Wang Z, Fu H, Xu J, Liu K. Increased expression of MUC3A is associated with poor prognosis in localized clear-cell renal cell carcinoma. Oncotarget. 2016; 7:50017-50026. doi: 10.18632/ oncotarget.10312.

23. Fu H, Liu Y, Xu L, Chang Y, Zhou L, Zhang W, Yang Y, $\mathrm{Xu}$ J. Low Expression of Mucin-4 Predicts Poor Prognosis in Patients With Clear-Cell Renal Cell Carcinoma. Medicine. 2016; 95:e3225.

24. Borzym-Kluczyk M, Radziejewska I, Cechowska-Pasko M. Increased expression of MUC1 and sialyl Lewis antigens in different areas of clear renal cell carcinoma. Clin Exp Nephrol. 2015; 19:732-737.

25. Gnemmi V, Bouillez A, Gaudelot K, Hemon B, Ringot B, Pottier N, Glowacki F, Villers A, Vindrieux D, Cauffiez C, Van Seuningen I, Bernard D, Leroy X, et al. MUC1 drives epithelial-mesenchymal transition in renal carcinoma through Wnt/beta-catenin pathway and interaction with SNAIL promoter. Cancer Lett. 2014; 346:225-236.

26. Aubert S, Fauquette V, Hemon B, Lepoivre R, Briez N, Bernard D, Van Seuningen I, Leroy X, Perrais M. MUC1, a new hypoxia inducible factor target gene, is an actor in clear renal cell carcinoma tumor progression. Cancer Res. 2009; 69:5707-5715.

27. Bouillez A, Gnemmi V, Gaudelot K, Hemon B, Ringot B, Pottier N, Glowacki F, Butruille C, Cauffiez C, Hamdane M, Sergeant N, Van Seuningen I, Leroy X, et al. MUC1-C nuclear localization drives invasiveness of renal cancer cells through a sheddase/gamma secretase dependent pathway. Oncotarget. 2014; 5:754-763. doi: 10.18632/ oncotarget.1768.

28. Shen LY, Wang H, Dong B, Yan WP, Lin Y, Shi Q, Chen KN. Possible prediction of the response of esophageal squamous cell carcinoma to neoadjuvant chemotherapy based on gene expression profiling. Oncotarget. 2016; 7:4531-4541. doi: 10.18632/oncotarget.6554.

29. Sheng YH, He Y, Hasnain SZ, Wang R, Tong H, Clarke DT, Lourie R, Oancea I, Wong KY, Lumley JW, Florin TH, Sutton P, Hooper JD, et al. MUC13 protects colorectal cancer cells from death by activating the NF-kappaB pathway and is a potential therapeutic target. Oncogene. 2016.

30. Lee HJ, Nam KT, Park HS, Kim MA, Lafleur BJ, Aburatani H, Yang HK, Kim WH, Goldenring JR. Gene expression profiling of metaplastic lineages identifies CDH17 as a prognostic marker in early stage gastric cancer. Gastroenterology. 2010; 139:213-225 e213.

31. Khan S, Ebeling MC, Zaman MS, Sikander M, Yallapu MM, Chauhan N, Yacoubian AM, Behrman SW, Zafar N, Kumar D, Thompson PA, Jaggi M, Chauhan SC. MicroRNA-145 targets MUC13 and suppresses growth and invasion of pancreatic cancer. Oncotarget. 2014; 5:7599-7609. doi: 10.18632/oncotarget.2821.

32. Ljungberg B, Bensalah K, Canfield S, Dabestani S, Hofmann F, Hora M, Kuczyk MA, Lam T, Marconi L, Merseburger AS, Mulders P, Powles T, Staehler M, Volpe A, Bex A. EAU guidelines on renal cell carcinoma: 2014 update. Eur Urol. 2015; 67:913-924. 
33. Kim SP, Alt AL, Weight CJ, Costello BA, Cheville JC, Lohse C, Allmer C, Leibovich BC. Independent validation of the 2010 American Joint Committee on Cancer TNM classification for renal cell carcinoma: results from a large, single institution cohort. J Urology. 2011; 185:2035-2039.

34. Karakiewicz PI, Trinh QD, de la Taille A, Abbou CC, Salomon L, Tostain J, Cindolo L, Artibani W, Ficarra V, Patard JJ. ECOG performance status 0 or 1 and symptom classification do not improve the ability to predict renal cell carcinoma-specific survival. Eur J Cancer. 2007; 43:1023-1029.

35. Xu L, Zhu Y, An H, Liu Y, Lin Z, Wang G, Xu J. Clinical significance of tumor-derived IL-1beta and IL-18 in localized renal cell carcinoma: Associations with recurrence and survival. Urol Oncol. 2015; 33:68 e69-16. 